
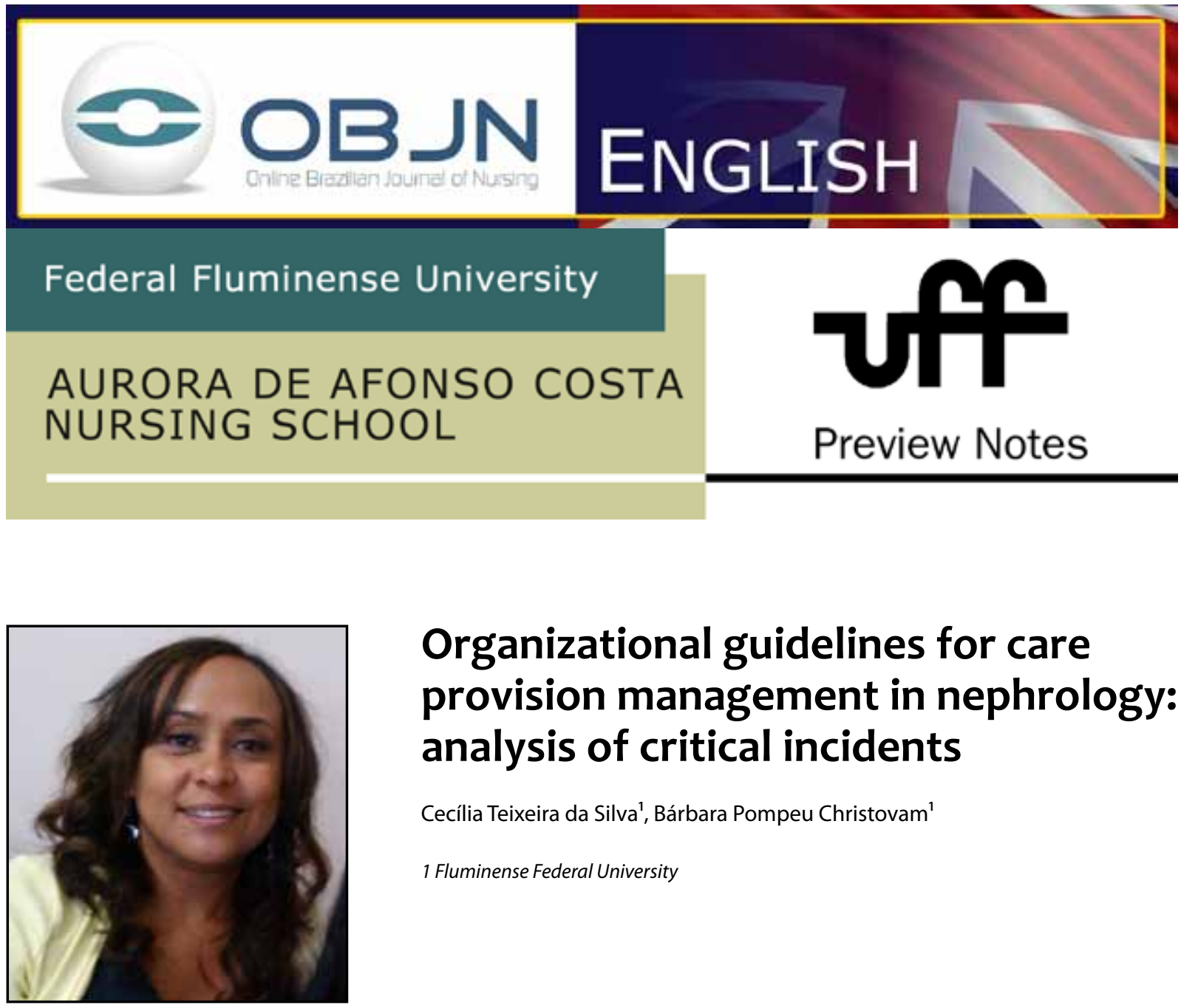

\title{
Organizational guidelines for care provision management in nephrology: analysis of critical incidents
}

\author{
Cecília Teixeira da Silva', Bárbara Pompeu Christovam ${ }^{1}$ \\ 1 Fluminense Federal University
}

\begin{abstract}
Overall aim: to propose organizational guidelines for the management actions associated with nursing care based on problem situations identified by nurses of the Nephrology and Renal Transplantation Center (CRNTR) via the analysis of critical incidents. Specific aims: To describe the management actions of care provision performed by nurses in the CRNTR; to characterize the problem situations faced by nurses performing care provision management actions in the CRNTR; to discuss problem situations, behaviors and consequences in the implementation of management actions of nursing care performed by nurses in the CRNTR. Method: a descriptive, qualitative-approach research, performed through the use of the Critical Incident Analysis (CIA) method. The data will be collected using semi-structured interviews with nurses of a university hospital CRNTR. For data analysis and organization, the Alceste 4.9 software will be used.
\end{abstract}

Descriptors: Nursing; Management of Patient Care; Management; Renal Dialysis.

Silva CT, Christovam BP. Organizational guidelines for care provision management in nephrology: analysis of critical incidents [internet] 2014 Oct [cited year month day]; 13 (suppl I): 431-4. Available from: http://www.objnursing.uff.br/index.php/ nursing/article/view/4981 


\section{SITUATION AND ITS SIGNIFICANCE}

Chronic Kidney Disease (CKD) is a disorder based on changes in the glomerular filtration rate and/or the presence of parenchymal lesions for at least three months. The disease has a poor prognosis, varied etiologies, many complications and high morbidity.

According to the Brazilian Society of Nephrology, the main underlying conditions of CKD among patients undergoing a dialysis program are hypertensive nephropathy (35\%), diabetes mellitus (30\%), glomerulonephritis (12\%) and polycystic kidney (4\%) (1). Brazil has the third largest incident of hemodialysis (HD) in the world. In 2013, the estimated number of patients in the chronic dialysis program totalled 100,397 , treated in 658 centers $^{(1)}$.

Managing care provision at the CRNTR in a public teaching hospital is a major challenge and requires from its managers/ administrators knowledge regarding all the processes in the institution, whether managerial, supportive or assistance. The Antonio Pedro University Hospital (HUAP) is a highly complex unit, serving the needs of a population of approximately two million people who need a type of service which involves high technology and costs and which is connected with other levels of health care. In the Brazilian Public Health System, about 30\% of the entire budget is spent on high-complexity procedures which serve only $3 \%$ of users ${ }^{(1)}$.

Despite concern about the significant increase in the conditions that lead to kidney disease (with increasingly higher treatment costs), and knowing that with the improvement in health care at all levels there is the possibility of intervening in the natural course of the disease, we observe a lack of studies in Brazil in terms of the epidemiological situa- tion as well as the managerial, administrative and economic aspects of services associated with the treatment.

The incipient scientific production highlights the need for nurses to use protocols as a tool to systematize care provision actions and the use of indicators as quality management tools, through the establishment of situational analysis and process improvement. In this way, the gap in knowledge about the management actions associated with nursing care in the CRNTR justifies and makes relevant the development of this study.

\section{STUDY SUBJECT}

The use of organizational directives as guidance tools with regard to care provision management actions performed by nurses in the CRNTR.

\section{GUIDING QUESTIONS}

What are the characteristics of the care management process performed by nurses in the CRNTR of HUAP? Which are the problem situations faced by nurses performing the actions of care provision management in this center? What are the situations that involve the management of nursing care, the behaviors of those involved, and the consequences of these situations for nurses of that center?

\section{AIMS}

Overall: to propose organizational guidelines for the guidance of the management actions associated with nursing care based 
on problem situations identified by nurses in the CRNTR through the analysis of critical incidents.

Specific: to describe the management actions associated with the provision of care performed by nurses in the CRNTR of HUAP; to characterize the problem situations faced by nurses performing the actions of care management in the CRNTR of HUAP; to discuss problem situations, behaviors and the consequences of the implementation of nursing care management actions performed by nurses in the CRNTR of HUAP.

\section{METHOD}

A qualitative-approach, descriptive research, conducted using Flanagan's Critical Incident Analysis (CIA) method ${ }^{(3)}$. The study area is the CRNTR in HUAP/UFF. Data collection will be undertaken using individual semi-structured interviews. Subjects will be the nurses who work in the study area. The possible sample consists of the eight nurses - the total number of nurses in service. Inclusion criteria: Nurses who have worked in the CRNTR/HUAP for at least one year. Exclusion criteria: professionals on vacation, licensed or absent from work for other reasons during the period of data collection. Data will be collected in the months of July and August 2014, using an interview script organized according to the Critical Incident Technique (TIC).

Data analysis is planned for the period from August to October 2014, using the Alceste 4.9 software as a tool to perform the analysis of the lexical content of the interviews. Themes emerging from the Alceste analysis will be grouped according to the categories that are developed from the Critical Incident Analysis: situations, behaviors and consequences.

This dissertation project is part of the Professional Master's Degree Program in Nursing Care of UFF, and is approved by Research Ethics Committee of Fluminense Federal University Medical School, with ID (CAAE) register: 30546614.7.0000.5243, and meets the provisions of Resolution No. 466/12.

\section{REFERENCES}

1. Sociedade Brasileira de Nefrologia. Censo de diálise SBN 2013 [internet]. [cited 27 Jul 2013]. Available from: http://www.sbn.org.br/pdf/ censo_2013-14-05.pdf.

2. Lima DVM. Research design: a contribution to the author. Online Braz J Nurs (Online) [internet]. 2011 Oct [cited 2014 Jul 26];10(2). Available from: http://www.objnursing.uff.br/ index.php/nursing/article/view/3648

3. Flanagan JC. The critical incident technique. Psychol Bull [internet]. 1954 Jul [cited 2014 Jun 20];51(4):1-33. Available from: https:// www.apa.org/pubs/databases/psycinfo/cit-article.pdf.

\footnotetext{
Authors' contribution:

Cecília Teixeira da Silva - author. Participated in the development and structuring of note, in writing and revising the article notes.

Bárbara Pompeu Christovam - Participated in the development and structuring the note.
} 
All authors participated in the phases of this publication in one or more of the following steps, in According to the recommendations of the International Committee of Medical Journal Editors (ICMJE, 2013): (a) substantial involvement in the planning or preparation of the manuscript or in the collection, analysis or interpretation of data; (b) preparation of the manuscript or conducting critical revision of intellectual content; (c) approval of the versión submitted of this manuscript. All authors declare for the appropriate purposes that the responsibilities related to all aspects of the manuscript submitted to OBJN are yours. They ensure that issues related to the accuracy or integrity of any part of the article were properly investigated and resolved. Therefore, they exempt the OBJN of any participation whatsoever in any imbroglios concerning the content under consideration. All authors declare that they have no conflict of interest of financial or personal nature concerning this manuscript which may influence the writing and/or interpretation of the findings. This statement has been digitally signed by all authors as recommended by the ICMJE, whose model is available in http://www. objnursing.uff.br/normas/DUDE_eng_13-06-2013.pdf

Received: 08/05/2014

Revised: 09/02/2014

Approved: 02/09/2014 